\title{
Quality of Life Effects of an Oral Fixed Combination of Netupitant and Palonosetron in Chemotherapy-Induced Nausea and Vomiting Prevention: Real-World Evidence in Patients with Breast Cancer Receiving Anthracycline- Cyclophosphamide-Based Chemotherapy
}

\author{
Jörg Schilling ${ }^{\mathrm{a}}$ Christian M. Kurbacher ${ }^{\mathrm{b}}$ Claus Hanusch $^{c}$ Steffi Busch $^{\mathrm{d}}$ \\ Martin Holländer ${ }^{\mathrm{e}}$ Janine Kreiss-Sender ${ }^{\mathrm{f}}$ Daniela Rezek $^{\mathrm{g}} \quad$ Elisa Flahaut $^{\mathrm{h}}$ \\ Meinolf Karthausi,j \\ ${ }^{a}$ Gynecological Oncology Practice, Berlin, Germany; ${ }^{b}$ Gynecology I (Gynecologic Oncology), Gynecologic Center \\ Bonn-Friedensplatz, Bonn, Germany; ' ${ }^{C}$ Department of Gynecology, Rotkreuzklinikum München, Munich, Germany; \\ ${ }^{\mathrm{d}}$ Gynecological Practice, Mühlhausen, Germany; ${ }^{\mathrm{e}}$ Gynecological Practice, Pirmasens, Germany; ${ }^{\mathrm{f}}$ Gynecological \\ Oncology Practice, Braunschweig, Germany; ${ }^{9}$ Breast Cancer Center Hamburg at Marien-Hospital Wesel, Wesel,

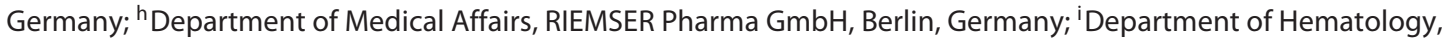 \\ Oncology and Palliative Care, Klinikum Neuperlach, Munich, Germany; ${ }^{j}$ Department of Hematology, Oncology and \\ Palliative Care, Klinikum Harlaching, Munich, Germany
}

\section{Keywords}

NEPA · Netupitant · Palonosetron · Chemotherapy-induced nausea and vomiting $\cdot$ Antiemetic $\cdot$ Real-world $\cdot$ Breast cancer

\begin{abstract}
Introduction: In a prospective non-interventional study involving 2,173 patients, we showed that use of the oral fixed combination of netupitant $300 \mathrm{mg}$ and palonosetron $0.5 \mathrm{mg}$ (NEPA) for prevention of chemotherapy (Ctx)-induced nausea and vomiting has beneficial effects on the quality of life (QoL) of patients with various types of cancers receiving highly or moderately emetogenic Ctx. Here, we report on the effects on QoL, effectiveness, and tolerability of NEPA in patients with breast cancer exposed to anthracycline-cyclophosphamide (AC)-based Ctx. Methods: This is a post hoc subanalysis of a prospective non-interventional study in 1,197 patients with breast cancer receiving up to 3 cycles of doxorubicin or epirubicin plus cyclophosphamide and NEPA.
\end{abstract}

NEPA administration was per the summary of product characteristics. Results: In cycle 1 of Ctx, a large proportion of patients (84\%) reported "no impact on daily life" (NIDL) due to vomiting; $53 \%$ of patients reported NIDL due to nausea. The complete response rate was $86 / 88 / 81 \%$ in the acute/delayed/overall phase in cycle 1, and NEPA was well tolerated throughout the study. Conclusion: The real-world beneficial effects of NEPA prophylaxis on QoL were confirmed for patients with breast cancer receiving AC. NEPA was effective with a good safety profile in this patient population in clinical practice.

(C) 2021 The Author(s) Published by S. Karger AG, Basel

\section{Introduction}

Anthracycline-cyclophosphamide (AC)-based chemotherapy (Ctx) was introduced for breast cancer treatment in the 1970s and has been widely associated with nausea, vomiting, and hair loss [1]. Ctx-induced

\section{karger@karger.com} www.karger.com/brc

Karger $\%$ BOPEN ACCESS
(C) 2021 The Author(s)

Published by S. Karger AG, Basel

This is an Open Access article licensed under the Creative Common Attribution-NonCommercial-4.0 International License (CC BY-NC) (http://www.karger.com/Services/OpenAccessLicense), applicable to the online version of the article only. Usage and distribution for commercial purposes requires written permission.
Correspondence to:

Jörg Schilling, dr.joerg.schilling@t-online.de 
nausea and vomiting (CINV) negatively impacts patients' quality of life (QoL), with nausea associated with early treatment discontinuation in patients with breast cancer [2, 3]. Optimal CINV management has been shown to improve the QoL and survival of patients with cancer [4].

For Ctx of early breast cancer, international guidelines recommend an anthracycline, typically doxorubicin or epirubicin, combined with cyclophosphamide followed or preceded by taxanes (paclitaxel or docetaxel) [5, 6]. AC is currently ranked as highly emetogenic Ctx (HEC) [79], and international CINV guidelines recommend prophylaxis comprising both a neurokinin-1 receptor antagonist $\left(\mathrm{NK}_{1} \mathrm{RA}\right)$ and a 5-hydroxytryptamine-3 (5- $\left.\mathrm{HT}_{3}\right)$ RA with obligatory addition of dexamethasone, and the possibility to add olanzapine for specific patients. In addition to the emetogenic potential of Ctx, patient- and disease-related factors, for example age $<60$ years, receiving cycle 1 or 2 of Ctx, anticipatory CINV, experiencing CINV in the previous cycle, use of non-prescribed agents in the previous cycle, platinum-anthracycline-based Ctx [10], and female gender [11], among others, can increase the CINV risk. While these risk factors for CINV have shown utility for therapy selection and are recognized in all antiemetic guidelines [12], they are usually not considered for development of antiemetic recommendations. Given that patients with breast cancer often have additional risk factors, such as being female and young (25\% are $<50$ years old), they are at particular risk of CINV [5, $6]$.

Low adherence to antiemetic guidelines in routine clinical practice is frequent and leads to suboptimal CINV control [13-15]. Factors such as low prescription rates and errors during home administration contribute to non-adherence $[14,16]$. Hence, use of complex antiemetic regimens is likely to impose a barrier to guidelines adherence [17]. The 3 approved oral $\mathrm{NK}_{1} \mathrm{RAs}$, aprepitant, rolapitant (no longer marketed in EU), and the oral fixed combination of the $\mathrm{NK}_{1} \mathrm{RA}$ netupitant $(300 \mathrm{mg})$ and the $5-\mathrm{HT}_{3} \mathrm{RA}$ palonosetron $(0.5 \mathrm{mg})$ (NEPA), differ in complexity of their administration schedules, in terms of number of doses, number of days, and doses of corticosteroids $[18,19]$.

Oral NEPA is the only available fixed-combination antiemetic and is approved for cisplatin-based HEC as well as AC-based HEC and moderately emetogenic Ctx (MEC; including carboplatin-based regimens) [20]. For patients receiving AC, a single dose of oral NEPA is administered with dexamethasone (12 mg) on the day of Ctx, providing effective protection covering the overall period (0-120 h) post-Ctx $[19,21]$. In a phase 3 study including patients with breast cancer who received AC $(n=1,412)$, oral NEPA-dexamethasone was significantly superior to palonosetron-dexamethasone for CINV control and had a good tolerability profile $[21,22]$. Importantly, significantly more patients in the NEPA group reported "no impact on daily life" (NIDL) due to nausea and vomiting [21]. In addition, a subanalysis from a second phase 3 safety trial in patients receiving HEC and MEC showed that NEPA-dexamethasone provided better CINV control in the subset of 39 patients with breast cancer compared with the overall population [22]. Recently, the safety of both the oral and intravenous NEPA formulations [20] was described in a phase 3 study $(n=402)$ in patients with breast cancer receiving AC. Both formulations had a favorable safety profile with no treatment-related injection-site adverse events (AEs) and high antiemetic efficacy. Importantly, most patients in both groups reported NIDL due to nausea and vomiting [23].

Clinical trials have shown that collection of patientreported outcomes regarding CINV can contribute to improved QoL and survival [4]. We conducted a non-interventional study in 2,173 patients throughout Germany to evaluate QoL in patients receiving antiemetic prophylaxis with NEPA for HEC and MEC under real-world conditions [24]. NEPA-based prophylaxis had a positive effect on the QoL of patients receiving HEC and MEC and was effective with a good tolerability profile in the real-world setting.

Herein, we report a post hoc subanalysis evaluating the effect of NEPA on the QoL of patients with breast cancer treated with AC who participated in the non-interventional study. NEPA effectiveness and safety were also analyzed.

\section{Methods}

\section{Study Design}

This is a post hoc analysis of a prospective non-interventional study conducted at 162 centers throughout Germany from September 2015 to March 2018 [24]. The primary endpoint was QoL in patients with breast cancer treated with AC who received NEPA antiemetic prophylaxis in daily practice. Secondary endpoints were NEPA effectiveness and safety.

Patients provided signed informed consent before enrollment, in compliance with the Declaration of Helsinki. The study was conducted in accordance with the German Medicines Act (Arzneimittelgesetz), and the Supreme Federal Authority, the Association of Accredited Physicians (Kassenärztliche Bundesvereinigung), the Central Federal Association of Statutory Health Insurance Funds (GKV-Spitzenverband), and the Association of Private Health Insurers (Verband der Privaten Krankenversicherung) were notified by OnkoDataMed GmbH (study No. CTU $130 \mathrm{~K}$ ).

\section{Patients and Procedures}

Patients were recruited between September 2015 and September 2017. Male and female adults ( $\geq 18$ years of age) with breast cancer scheduled to receive NEPA prophylaxis for CINV associated with $\mathrm{AC}$ were included in this subanalysis. Patients receiving Ctx other than AC for breast cancer were excluded. Details on patient eligibility were described previously [24]. 
Fig. 1. Relative frequencies of patients experiencing no influence on daily life activities due to nausea, vomiting, or combined nausea and vomiting, by cycle: subanalysis population. NIDL, no impact on daily life.

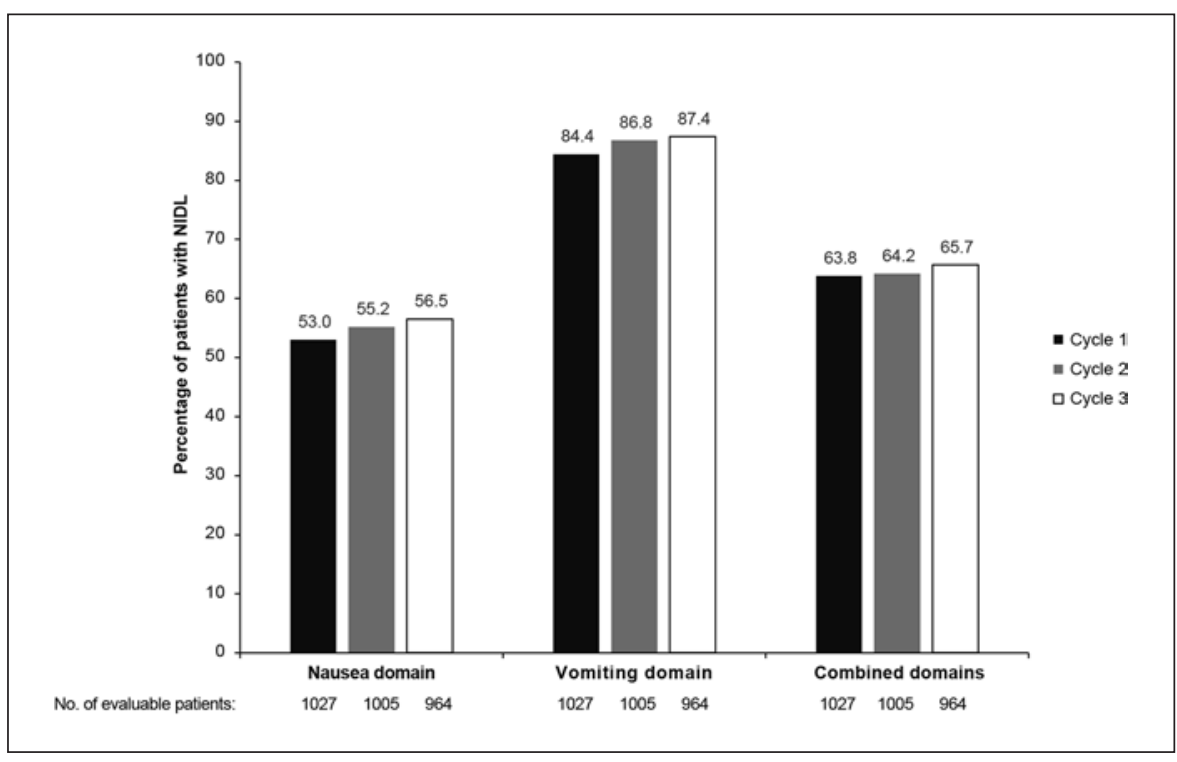

Table 1. Patient demographics and baseline characteristics: subanalysis population

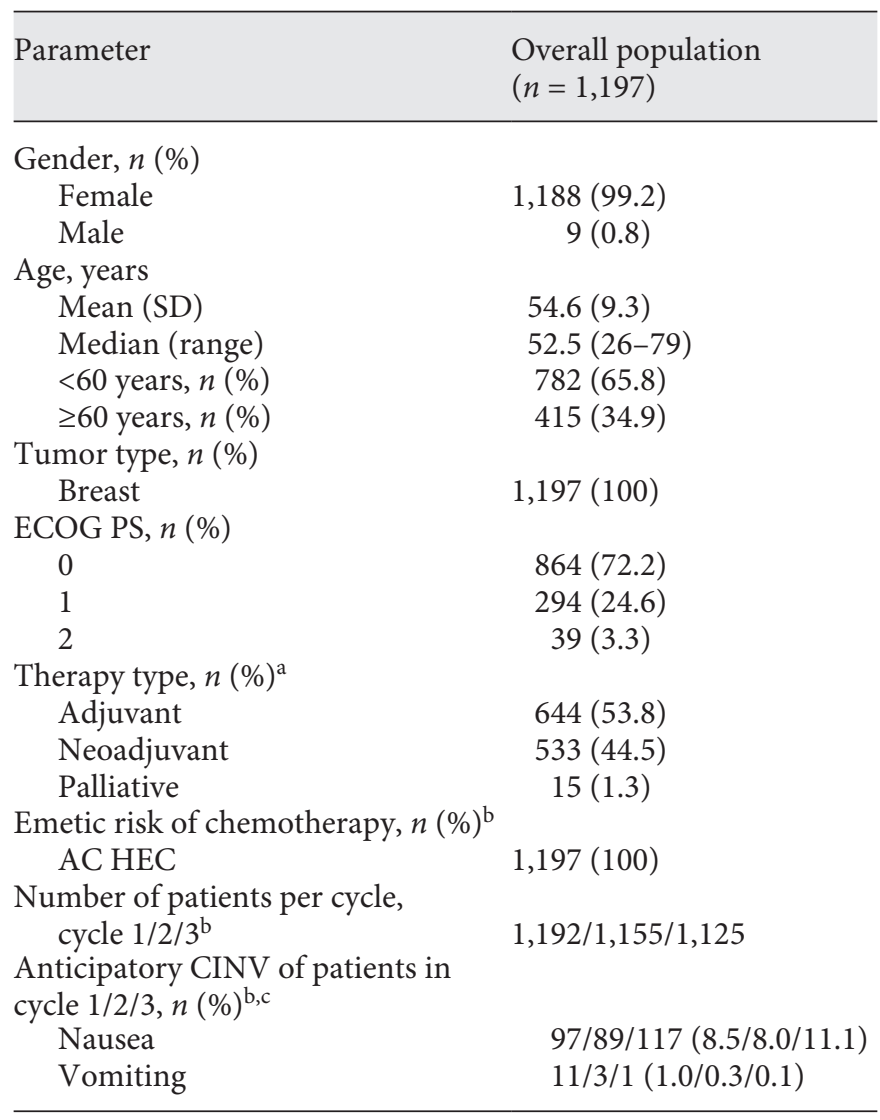

AC, anthracycline-cyclophosphamide; CINV, chemotherapyinduced nausea and vomiting; ECOG PS, Eastern Cooperative Oncology Group performance status; HEC, highly emetogenic chemotherapy.

${ }^{\text {a }}$ Patients receiving multiple therapies at cycles 1,2, and 3 could be assigned to multiple categories.

$\mathrm{b}$ Patients not documented in the electronic case report form were excluded.

${ }^{\mathrm{c}}$ Nausea and vomiting directly before the start of chemotherapy.
NEPA was administered as per the summary of product characteristics, i.e., one oral NEPA dose $1 \mathrm{~h}$ before the start of each AC cycle combined with $12 \mathrm{mg}$ of dexamethasone. The study did not influence physicians' clinical practice and did not modify patients' treatment.

\section{Assessments}

For QoL, the impact of nausea and vomiting on daily life was measured using the Functional Living Index-Emesis (FLIE) questionnaire, which was completed by patients on days $1-5$ of each cycle. Individual patients' data were collected in electronic case report forms during 3 Ctx cycles. Details on QoL, effectiveness, and safety assessments were described previously [24].

\section{Statistical Analysis}

No statistical analyses were performed. Descriptive statistics for demographic, QoL, effectiveness, and safety data are presented. Analysis and handling of missing data of FLIE questionnaires were described previously [24]. Complete response (CR) was defined as no emesis and no need for additional rescue medication. No significant nausea (NSN) was defined as no or mild nausea (grade 1) according to Common Terminology Criteria for Adverse Events version 4.03 . Patients were stratified by age ( $<60$ vs. $\geq 60$ years). QoL and effectiveness were analyzed for each group.

\section{Results}

\section{Patients}

Among the 2,173 patients included in the final analysis of the non-interventional study [24], a total of 1,430 (66\%) had breast cancer, of whom 1,197 (84\%) received AC and constituted the subanalysis population. Most patients were female (99\%) and the median age was 52.5 years (range 26-79), with 66\% younger than 60 years (Table 1; online suppl. Table 1; for all online suppl. material, see www.karger.com/doi/10.1159/000514891). For $54 / 45 / 1 \%$ of patients, AC was administered in the adjuvant/neoadjuvant/palliative settings, respectively. 
Table 2. Effectiveness outcomes by chemotherapy cycle

\begin{tabular}{|c|c|c|c|}
\hline Parameter & Cycle 1 & Cycle 2 & Cycle 3 \\
\hline \multicolumn{4}{|l|}{$\mathrm{CR}^{\mathrm{a}}$} \\
\hline Acute & 86.0 & 86.9 & 88.3 \\
\hline Delayed & 88.2 & 87.2 & 86.0 \\
\hline Overall & 81.0 & 81.7 & 81.1 \\
\hline \multicolumn{4}{|l|}{ No emesis ${ }^{b}$} \\
\hline Acute & 94.2 & 95.1 & 96.2 \\
\hline Delayed & 97.1 & 96.7 & 96.9 \\
\hline Overall & 92.8 & 93.5 & 94.4 \\
\hline \multicolumn{4}{|c|}{ No significant nausea $^{c}$} \\
\hline Acute & 69.1 & 73.9 & 76.0 \\
\hline Delayed & 72.7 & 71.5 & 70.1 \\
\hline Overall & 60.1 & 61.8 & 62.4 \\
\hline \multicolumn{4}{|l|}{ No nausea ${ }^{c}$} \\
\hline Acute & 43.3 & 47.1 & 49.8 \\
\hline Delayed & 39.7 & 40.8 & 41.6 \\
\hline Overall & 31.1 & 33.6 & 35.7 \\
\hline \multicolumn{4}{|c|}{ No rescue medication ${ }^{\mathrm{d}}$} \\
\hline Acute & 90.2 & 90.3 & 91.6 \\
\hline Delayed & 90.1 & 89.0 & 88.6 \\
\hline Overall & 85.6 & 85.4 & 86.0 \\
\hline
\end{tabular}

Values are the percentage of patients. CR, complete response.

${ }^{a}$ Number of evaluable patients in cycles $1 / 2 / 3$ by phase: acute, $1,120 / 1,092 / 1,047$; delayed, 1,093/1,067/1,023; overall, 1,075/ $1,055 / 1,023$.

${ }^{\mathrm{b}}$ Number of evaluable patients in cycles $1 / 2 / 3$ by phase: acute, 1,120/1,092/1,047; delayed, 1,093/1,067/1,023; overall, 1,075/ $1,055 / 1,013$.

${ }^{\mathrm{c}}$ Number of evaluable patients in cycles $1 / 2 / 3$ by phase: acute, $1,130 / 1,102 / 1,057$; delayed, $1,119 / 1,093 / 1,044$; overall, $1,103 /$ $1,085 / 1,038$.

${ }^{\mathrm{d}}$ Number of evaluable patients in cycles $1 / 2 / 3$ by phase: acute, $1,162 / 1,159 / 1,163$; delayed, $1,150 / 1,111 / 1,066$; overall, $1,150 /$ $1,111 / 1,066$.

\section{Quality of Life}

FLIEquestionnairesfrom $1,027 / 1,005 / 964(86 / 87 / 86 \%)$ patients were analyzed in cycles $1 / 2 / 3$, respectively. In cycle 1 , NIDL due to vomiting was reported by $84 \%$ of patients, $53 \%$ of patients reported NIDL due to nausea, and $64 \%$ of patients had NIDL due to combined nausea and vomiting. These rates were maintained with a slight numeric increase in subsequent cycles (Fig. 1).

Nausea and vomiting had a greater impact on the daily life of patients $<60$ vs. $\geq 60$ years (online suppl. Fig. 1). NIDL due to nausea, vomiting, and combined domains improved consistently from cycle 1 to 3 in both age categories, with the largest numeric improvements observed in younger patients.

\section{Effectiveness}

In cycle 1 , the $C R$ rate was 86,88 , and $81 \%$ in the acute $(0-24 \mathrm{~h})$, delayed $(24-120 \mathrm{~h})$, and overall $(0-120 \mathrm{~h})$ periods post-Ctx; these high response rates were maintained in cycles 2 and 3 (Table 2). The rate of no emesis in the acute, delayed, and overall periods was $\geq 93 \%$ during the 3 cycles. Both NSN and no nausea rates increased numerically across cycles in all phases, except for NSN in the delayed phase. In cycle 1 , rescue medication was needed for 10,10 , and $14 \%$ of patients in the acute, delayed, and overall phases, respectively, and the low rates were maintained in cycles 2 and 3. CR and NSN outcomes were consistently higher in the group of patients $\geq 60$ vs. $<60$ years throughout the cycles (online suppl. Fig. 2, 3).

The effectiveness of NEPA prophylaxis was rated as "very good" or "good" by the vast majority of physicians $(>86 \%)$ and patients (>84\%) in all 3 Ctx cycles analyzed (online suppl. Fig. 4). The perceptions of NEPA effectiveness by both patients and treating physicians were similar in patients $<60$ and $\geq 60$ years (online suppl. Fig. 5).

\section{Safety}

In total, $386(32 \%)$ patients reported treatment-emergent AEs during the study period, with 116 (10\%) experiencing NEPA treatment-related AEs (Table 3). The most common treatment-related AEs were fatigue $(5 \%)$ and constipation (4\%). Among 71 (6\%) patients reporting serious AEs, the toxicity was considered to be related to NEPA in $5(0.4 \%)$ patients. Specifically, diarrhea (grade 4$)$, febrile neutropenia (grade 3 ), and serotonin syndrome leading to depression and suicide attempt (grade 4) occurred in 1 patient each, with all patients recovering within 3-5 days; 1 patient with constipation grade 1 recovered after 43 days and 1 patient with pancytopenia (grade 3 ) was recovering at the time of the safety report. No deaths or other relevant safety signals related to NEPA were reported.

\section{Discussion}

Patients with breast cancer are generally highly susceptible to CINV, due to patient- and Ctx-related risk factors, for example they are mainly female, of young age, and receiving $\mathrm{AC}[5,6,10,11,25]$. This post hoc subgroup analysis from a prospective non-interventional study in patients with various tumor types receiving HEC/MEC treatment aimed to evaluate the effects of NEPA prophylaxis specifically in patients with breast cancer receiving AC treatment [24].

NEPA prophylaxis was evaluated in a total of 1,197 patients with diverse demographic and disease characteristics under routine clinical practice conditions. Most patients were female (99\%) and the median age was 52.5 years ( $66 \%$ of patients were $<60$ years). QoL (the primary endpoint) outcomes revealed that CINV was generally well controlled in cycle 1 . Vomiting had NIDL for most patients $(84 \%)$, whereas a lower proportion of patients reported NIDL due to nausea (53\%); $64 \%$ of patients had 
Table 3. Summary of AEs by chemotherapy cycle and overall

\begin{tabular}{|c|c|c|c|c|}
\hline & $\begin{array}{l}\text { Cycle 1 } \\
(n=1,192)\end{array}$ & $\begin{array}{l}\text { Cycle } 2 \\
(n=1,155)\end{array}$ & $\begin{array}{l}\text { Cycle } 3 \\
(n=1,125)\end{array}$ & $\begin{array}{l}\text { Overall } \\
(n=1,197)\end{array}$ \\
\hline Treatment-emergent AEs & $286(24.0)$ & $225(19.5)$ & $137(12.2)$ & $386(32.2)$ \\
\hline Treatment-related AEs ${ }^{\mathrm{a}}$ & $81(6.8)$ & $55(4.8)$ & $28(2.5)$ & $116(9.7)$ \\
\hline Serious AEs & $3(0.3)$ & $2(0.2)$ & $0(0)$ & $71(5.9)$ \\
\hline Serious treatment-related $\mathrm{AEs} \mathrm{s}^{\mathrm{b}}$ & $3(0.3)$ & $2(0.2)$ & $0(0)$ & $5(0.4)$ \\
\hline Treatment-related AEs ${ }^{\mathrm{a}}$ leading to death & $0(0)$ & $0(0)$ & $0(0)$ & $0(0)$ \\
\hline \multicolumn{5}{|l|}{ Treatment-related $\mathrm{AEs}^{\mathrm{a}}$ in $>1 \%$ of patients } \\
\hline Fatigue & $38(3.2)$ & $9(0.8)$ & $8(0.7)$ & $54(4.5)$ \\
\hline Constipation & $33(2.8)$ & $22(1.9)$ & $4(0.4)$ & $52(4.3)$ \\
\hline Insomnia & $25(2.1)$ & $9(0.8)$ & $1(0.1)$ & $35(2.9)$ \\
\hline Nausea & $10(0.8)$ & $14(1.2)$ & $10(0.9)$ & $25(2.1)$ \\
\hline Headache & $9(0.8)$ & $6(0.5)$ & $3(0.3)$ & $17(1.4)$ \\
\hline
\end{tabular}

NIDL due to combined nausea and vomiting. Overall, QoL outcomes were maintained in subsequent cycles, showing a slight but consistent improvement in all domains. These results nearly mirror our previous report of the whole population receiving various HEC regimens [24], including the patients receiving AC presented in this subanalysis (86\%), cisplatin-based regimens (13\%), and AC for other solid tumors (1\%). Our results suggest that the benefit of NEPA on QoL outcomes may be generalized to various HEC regimens. Notably, our real-world results are in line with previous observations from randomized controlled trials in Ctx-naive patients with breast cancer (online suppl. Table 2) [22, 23].

Similarly, the antiemetic effectiveness of NEPA in terms of rates of $\mathrm{CR}$, no emesis, and no need for rescue medication was high and comparable with that reported for the overall population [24]. These outcomes also align with previous reports from randomized phase 3 clinical trials in patients with breast cancer receiving AC (online suppl. Table 3) [22, 23, 26, 27].

Antiemetic effectiveness in terms of NSN was lower than that observed in randomized controlled trials, especially in the acute phase. Enrollment of Ctx non-naive patients, who have a higher likelihood of added comorbidities and are excluded from controlled trials, may partially account for this difference. Nevertheless, NSN and nonausea rates in this analysis were slightly lower compared with the overall population receiving HEC/MEC [24]. This highlights the high prophylactic needs and special challenge for nausea control in patients with breast cancer receiving AC $[28,29]$. While delayed nausea can occur in $73-82 \%$ of women with breast cancer receiving mostly AC in the absence of an $\mathrm{NK}_{1} \mathrm{RA}$-based prophylaxis [28], NEPA-dexamethasone is the only $\mathrm{NK}_{1} \mathrm{RA}$ regimen that has shown a consistent benefit in nausea control versus prophylaxis with $5-\mathrm{HT}_{3} \mathrm{RA}$-dexamethasone $[21,22,30]$.

The antiemetic effects of NEPA are extended to patients who are at higher risk for CINV and generally excluded from clinical trials, including those with anticipatory nausea (8\%) and those non-naive to Ctx who may have experienced CINV previously, which may account for the slight differences observed between randomized controlled trials and the present study. Of note, $66 \%$ of patients were $<60$ years of age, and, as expected, both QoL and effectiveness outcomes were lower in this age group compared with patients $\geq 60$ years.

Recent studies have analyzed the effectiveness of aprepitant-based prophylaxis in the real world. In a retrospective study including 1,247 Ctx-naive patients receiving AC for breast cancer, prophylaxis with aprepitant-palonosetron-dexamethasone resulted in no CINV events in $61 \%$ of patients [31]. While a direct comparison of effectiveness between studies cannot be done, our analysis showed an overall $81 \%$ CR rate in patients naive and nonnaive to Ctx. The more complex administration schedule of aprepitant-based regimens, which require home administration of aprepitant on days 2 and 3 after Ctx and dexamethasone on days 2-4 [32], may be more difficult to implement in the real world than NEPA.

In the present analysis, antiemetic effectiveness of NEPA was ranked mostly as "very good" both by physicians and patients in the 3 Ctx cycles analyzed. Contrary to previous reports, our study showed a good correlation between patients' and physicians' perceptions [16].

NEPA was well tolerated under real-world conditions in patients with various comorbidities, many of whom required concomitant medication, and the safety profile was in line with that from pivotal trials $[21,23]$. It is note- 
worthy that common AEs occurring during Ctx were categorized as NEPA related by the investigator.

The potential for cardiac toxicity limits the cumulative dose of anthracyclines for treatment of breast cancer and restricts the choice of concomitant medication [33]. While cardiac toxicity is a class AE of first-generation $5-\mathrm{HT}_{3} \mathrm{RAs}$ [18], the second-generation $5-\mathrm{HT}_{3} \mathrm{RA}$ palonosetron included in NEPA is not associated with cardiotoxic effects [19]. Accordingly, the frequency of clinically relevant cardiotoxic events was low $(0.7 \%)$ in this analysis.

In conclusion, this post hoc analysis demonstrates that prophylaxis with NEPA in patients with breast cancer receiving $\mathrm{AC}$ is associated with favorable effects on QoL and is effective with a good safety profile in the real-world setting as previously observed in pivotal trials, supporting the use of NEPA in this population in daily clinical practice.

\section{Acknowledgments}

The authors thank the volunteers, investigators, and study teams. We thank Dr. Silvia Olivari from Helsinn Healthcare SA for her contributions in the development of the manuscript. Editorial support and medical writing assistance were provided by Iratxe Abarrategui, $\mathrm{PhD}$, CMPP, from Aptitude Health, The Hague, the Netherlands, funded by RIEMSER Pharma GmbH, Berlin, Germany. The authors are fully responsible for all content and editorial decisions for this manuscript.

\section{Statement of Ethics}

Patients provided signed informed consent before enrollment, in compliance with the Declaration of Helsinki. The study was conducted in accordance with the German Medicines Act (Arzneimittelgesetz), and the Supreme Federal Authority, the Association of Accredited Physicians (Kassenärztliche Bundesvereinigung), the Central Federal Association of Statutory Health Insurance Funds (GKV-Spitzenverband), and the Association of Private Health Insurers (Verband der Privaten Krankenversicherung) were notified by OnkoDataMed GmbH (study No. CTU 130 K).

\section{Conflict of Interest Statement}

J.S.: honoraria, travel expenses, RIEMSER Pharma GmbH. C.M.K.: honoraria, Amgen, Eli Lilly, Novartis, Mundipharma, Pfizer, PharmaMar, RIEMSER, Roche, Tesaro; consulting or advisory role, Amgen, Axios, Eli Lilly, Hilotherm, Mundipharma, NewCo, Novartis, Pfizer, RIEMSER, Roche, Tesaro; research funding, AstraZeneca, Axios, MSD Sharp \& Dohme (Merck), NewCo, Novartis, Pfizer, PharmaMar, RIEMSER, Seattle Genetics, Immunomedics; travel, accommodations, expenses, Amgen, Hexal, Immunomedics, Pfizer, PharmaMar, Tesaro, Teva Oncology. C.H.: advisory board, AstraZeneca, Lilly, Pfizer, Roche. S.B.: lectures, studies and support for congress participation, Amgen, Roche, Novartis, Pfizer, Riemser, Lilly, Clovis, GSK, Onkovis, AstraZeneca, MSD. M.H.: honoraria, Pfizer, AstraZeneca, iOMEDICO, MMF, Amgen; research funding, RIEMSER, Indivumed. J.K.S. and D.R.: nothing to disclose. E.F.: RIEMSER employee. M.K.: ad board, travel grant, Helsinn Healthcare, RIEMSER Pharma $\mathrm{GmbH}$.

\section{Funding Sources}

The study described within this paper was sponsored by RIEMSER Pharma GmbH, Berlin, Germany. RIEMSER Pharma GmbH also participated in the writing, review, and approval of the manuscript.

\section{Author Contributions}

J.S., C.M.K., C.H., S.B., M.H., J.K.-S., D.R., and M.K. participated in the conceptualization of the study, investigation, preparation of the original draft, and manuscript review and editing. E.F. participated in the conceptualization of the study, project administration and supervision, preparation of the original draft, and manuscript review and editing.

\section{Availability of Data}

Individual patient-level data will not be shared.

\section{References}

1 Brambilla C, De Lena M, Bonadonna G. Combination chemotherapy with adriamycin (NSC-123127) in metastatic mammary carcinoma. Cancer Chemother Rep. 1974 MarApr;58(2):251-3.

2 Cohen L, de Moor CA, Eisenberg P, Ming EE, $\mathrm{Hu} \mathrm{H}$. Chemotherapy-induced nausea and vomiting: incidence and impact on patient quality of life at community oncology settings. Support Care Cancer. 2007 May;15(5): 497-503.

3 Richardson LC, Wang W, Hartzema AG, Wagner S. The role of health-related quality of life in early discontinuation of chemotherapy for breast cancer. Breast J. 2007 NovDec;13(6):581-7.
4 Basch E, Deal AM, Dueck AC, Scher HI, Kris MG, Hudis C, et al. Overall survival results of a trial assessing patient-reported outcomes for symptom monitoring during routine cancer treatment. JAMA. 2017 Jul;318(2):197-8.

5 National Comprehensive Cancer Network. NCCN Clinical Practice Guidelines in Oncology (NCCN Guidelines ${ }^{\circledR}$ ). Breast cancer. Version 6. 2020.

6 Cardoso F, Kyriakides S, Ohno S, PenaultLlorca F, Poortmans P, Rubio IT, et al.; ESMO Guidelines Committee. Electronic address: clinicalguidelines@esmo.org. Early breast cancer: ESMO Clinical Practice Guidelines for diagnosis, treatment and follow-up. Ann Oncol. 2019 Aug;30(8):1194-220.
7 Multinational Association of Supportive Care in Cancer. MASCC/ESMO antiemetic guideline 2016. With updates in 2019. Available from: https://www.mascc.org/assets/Guidelines-Tools/mascc_antiemetic_guidelines_ english_v.1.5SEPT29.2019.pdf.

8 Hesketh PJ, Kris MG, Basch E, Bohlke K, Barbour SY, Clark-Snow RA, et al. Antiemetics: ASCO Guideline Update. J Clin Oncol. 2020 Aug;38(24):2782-97.

9 National Comprehensive Cancer Network. NCCN Clinical Practice Guidelines in Oncology (NCCN Guidelines ${ }^{\circledR}$ ). Antiemesis. Version 2.2020 . 
10 Dranitsaris G, Molassiotis A, Clemons M, Roeland E, Schwartzberg L, Dielenseger P, et al. The development of a prediction tool to identify cancer patients at high risk for chemotherapy-induced nausea and vomiting. Ann Oncol. 2017 Jun;28(6):1260-7.

11 Osoba D, Zee B, Pater J, Warr D, Latreille J, Kaizer L. Determinants of postchemotherapy nausea and vomiting in patients with cancer. Quality of Life and Symptom Control Committees of the National Cancer Institute of Canada Clinical Trials Group. J Clin Oncol. 1997 Jan;15(1):116-23.

12 Clemons M, Bouganim N, Smith S, Mazzarello S, Vandermeer L, Segal R, et al. Risk model-guided antiemetic prophylaxis vs physician's choice in patients receiving chemotherapy for early-stage breast cancer: A randomized clinical trial. JAMA Oncol. 2016 Feb;2(2):225-31.

13 Aapro M, Molassiotis A, Dicato M, Peláez I, Rodríguez-Lescure Á, Pastorelli D, et al.; PEER investigators. The effect of guidelineconsistent antiemetic therapy on chemotherapy-induced nausea and vomiting (CINV): the Pan European Emesis Registry (PEER). Ann Oncol. 2012 Aug;23(8):1986-92.

14 Aapro M, Ruffo P, Panteri R, Costa S, Piovesana $\mathrm{V}$. Oncologist perspectives on chemotherapy-induced nausea and vomiting (CINV) management and outcomes: A quantitative market research-based survey. Cancer Rep. 2018 Dec;1(4):e1127.

15 Aapro MS, Chrápavá M, Curca ROD, Gales L, Calim A, Grigorescu AC, et al. Assessing the impact of antiemetic guideline compliance on prevention of chemotherapy-induced nausea and vomiting (CINV): Results of the Nausea/ Emesis Registry in Oncology (NERO). J Clin Oncol. 2020;38(suppl 15): abstract 12083.

16 Vidall C, Fernández-Ortega $\mathrm{P}$, Cortinovis D, Jahn P, Amlani B, Scotté F. Impact and management of chemotherapy/radiotherapy-induced nausea and vomiting and the perceptual gap between oncologists/oncology nurses and patients: a cross-sectional multinational survey. Support Care Cancer. 2015 Nov;23(11):3297-305.
17 European Medicines Agency. Guideline on clinical development of fixed combination medicinal products. EMA/CHMP/158268/2017. Available from: https://www.ema.europa.eu/ en/documents/scientific-guideline/guidelineclinical-development-fixed-combination-medicinal-products-revision-2_en.pdf.

18 Navari RM, Aapro M. Antiemetic prophylaxis for chemotherapy-induced nausea and vomiting. N Engl J Med. 2016 Apr;374(14):1356-67.

19 Aapro M, Zhang L, Yennu S, LeBlanc TW, Schwartzberg L. Preventing chemotherapyinduced nausea and vomiting with netupitant/palonosetron, the first fixed combination antiemetic: current and future perspective. Future Oncol. 2019 Apr;15(10):1067-84.

20 Akynzeo 300 mg/0.50 mg hard capsules; Akynzeo $235 \mathrm{mg} / 0.25 \mathrm{mg}$ powder for concentrate for solution for infusion [summary of product characteristics] Dublin, Ireland: Helsinn Birex Pharmaceuticals Ltd.; 2020.

21 Aapro M, Rugo H, Rossi G, Rizzi G, Borroni $\mathrm{ME}$, Bondarenko I, et al. A randomized phase III study evaluating the efficacy and safety of NEPA, a fixed-dose combination of netupitant and palonosetron, for prevention of chemotherapy-induced nausea and vomiting following moderately emetogenic chemotherapy. Ann Oncol. 2014 Jul;25(7):1328-33.

22 Rugo HS, Rossi G, Rizzi G, Aapro M. Efficacy of NEPA (netupitant/palonosetron) across multiple cycles of chemotherapy in breast cancer patients: A subanalysis from two phase III trials. Breast. 2017 Jun;33:76-82.

23 Schwartzberg L, Navari R, Clark-Snow R, Arkania E, Radyukova I, Patel K, et al. Phase IIIb safety and efficacy of intravenous NEPA for prevention of chemotherapy-induced nausea and vomiting (CINV) in patients with breast cancer receiving initial and repeat cycles of anthracycline and cyclophosphamide (AC) chemotherapy. Oncologist. 2020 Mar;25(3): e589-97.

24 Karthaus M, Oskay-Özcelik G, Wülfing P, Hielscher C, Guth D, Zahn MO, et al. Realworld evidence of NEPA, netupitant-palonosetron, in chemotherapy-induced nausea and vomiting prevention: effects on quality of life. Future Oncol. 2020 May;16(14):939-53.
25 Thomssen C, Lüftner D, Untch M, Haidinger R, Würstlein R, Harbeck N, et al. International consensus conference for advanced breast cancer, Lisbon 2019: ABC5 consensus - assessment by a German group of experts. Breast Care. 2020 Feb;15(1):82-95.

26 Aapro M, Schwartzberg L. Efficacy of intravenous (IV) NEPA and oral NEPA, fixed NK1/5-HT3 receptor antagonist combination agents, for prevention of chemotherapyinduced nausea and vomiting following anthracycline-cyclophosphamide (AC)-based chemotherapy. San Antonio Breast Cancer Symposium. December 10-14, 2019; San Antonio, TX. Poster P2-12-04.

27 Schwartzberg L, Voisin D, Rizzi G, Patel K, Aapro M. Safety of intravenous (IV) NEPA and oral NEPA for prevention of CINV in patients with breast cancer receiving anthracycline/cyclophosphamide (AC) chemotherapy. Support Care Cancer. 2019;27 suppl 1:S41.

28 Dibble SL, Isreal J, Nussey B, Casey K, Luce J. Delayed chemotherapy-induced nausea in women treated for breast cancer. Oncol Nurs Forum. 2003 Mar-Apr;30(2):E40-7.

29 Dranitsaris G, Mazzarello S, Smith S, Vandermeer L, Bouganim N, Clemons M. Measuring the impact of guideline-based antiemetic therapy on nausea and vomiting control in breast cancer patients with multiple risk factors. Support Care Cancer. 2016 Apr;24(4):1563-9.

30 Bošnjak SM, Gralla RJ, Schwartzberg L. Prevention of chemotherapy-induced nausea: the role of neurokinin-1 (NK1) receptor antagonists. Support Care Cancer. 2017 May; 25(5):1661-71.

31 Schwartzberg LS, Marks SM, Gabrail NY, Geller RB, Kish J. Real-world effectiveness of palonosetron-based antiemetic regimens: preventing chemotherapy-induced nausea and vomiting. J Comp Eff Res. 2019 Jul;8(9):657-70.

32 Emend (aprepitant) capsules, for oral use; Emend (aprepitant) for oral suspension [prescribing information] Whitehouse Station: Merck Sharp \& Dohme Corp.; 2019.

33 McGowan JV, Chung R, Maulik A, Piotrowska I, Walker JM, Yellon DM. Anthracycline chemotherapy and cardiotoxicity. Cardiovasc Drugs Ther. 2017 Feb;31(1):63-75. 